\title{
Produção de serapilheira em Floresta Ombrófila Mista, em São Francisco de Paula, Rio Grande do Sul, Brasil
}

\author{
A. Backes ${ }^{1,3}$, Felipe L. Prates ${ }^{2}$ e Mariana G. Viola ${ }^{2}$
}

Recebido em 25/11/2003. Aceito em 12/08/2004

\begin{abstract}
RESUMO-(Produção de serapilheira em Floresta Ombrófila Mista, em São Francisco de Paula, Rio Grande do Sul, Brasil). A presente pesquisa visou avaliar a dinâmica de produção, acúmulo e decomposição de serapilheira de um remanescente de Floresta Ombrófila Mista, na Floresta Nacional de São Francisco de Paula, localizada no município de São Francisco de Paula, Estado do Rio Grande do Sul, Brasil. A Floresta Nacional está localizada entre as coordenadas $29^{\circ} 24^{\prime}$ e e $29^{\circ} 27^{\prime} \mathrm{S}$ e $50^{\circ} 22^{\prime}$ e $50^{\circ} 25^{\prime} \mathrm{W}$ e sua altitude máxima é de $923 \mathrm{~m}$. $\mathrm{O}$ fragmento de Floresta Ombrófila Mista, objeto do presente estudo, é formado por numerosos espécimes de Araucaria angustifolia (Bertol.) Kuntze, e por diversas espécies consorciadas, entre as quais destacam-se Blepharocalyx salicifolius (H.B. \& K.) Berg, Ilex paraguariensis A.St.-Hil., Tabebuia umbellata (Sond.) Sandwith e várias espécies dos gêneros Ocotea e Nectandra. A produção de serapilheira foi avaliada por coletas mensais, durante dois anos, com o auxílio de 15 coletores de $0,80 \times 1 \mathrm{~m}$, distribuídos num hectare de floresta. A serapilheira acumulada foi avaliada pela coleta, em 72 pontos diferentes, de todo o material vegetal reconhecido como tal, depositado sobre o solo florestal, numa área de um metro quadrado, em cada ponto. A taxa de decomposição foi calculada pela relação entre o total anual de serapilheira produzida e o total acumulado A floresta produziu, em média, 10.305,88kg/ha/ano de serapilheira, e acumula, em média, $14.296,00 \mathrm{~kg} / \mathrm{ha}$. O tempo necessário para decompor $50 \%$ foi de 316 dias com uma taxa de decomposição correspondente a $\mathrm{K}=0,86$.
\end{abstract}

Palavras-chave: floresta ombrófila mista, Araucaria angustifolia, floresta nacional, serapilheira, decomposição

\begin{abstract}
Litterfall in a Araucaria angustifolia forest in São Francisco de Paula, Rio Grande do Sul, Brazil). The present work was conducted out in São Francisco de Paula National Forest, located in the municipality of São Francisco de Paula, Rio Grande do Sul State, Brazil, at ca. $29^{\circ} 24^{\prime}$ to $29^{\circ} 27^{\prime} \mathrm{S}$ and $50^{\circ} 22^{\prime}$ to $50^{\circ} 25^{\prime} \mathrm{W}$ and the maximum altitude of $923 \mathrm{~m}$. The objective of this work was to avaluate the production, accumlation and decomposition of litter in a Araucaria angustifolia forest in south Brazil. The forest presented numerous specimens of Araucaria angustifolia (Bertol.) Kuntze, Blepharocalyx salicifolius (H.B. \& K.) Berg, Ilex paraguariensis A.St.-Hil., Tabebuia umbellata (Sond.) Sandwith and diferents species of the genera Ocotea and Nectandra. The litter fall was evalueted through monthly collections employing 15 litter traps $(0.80 \times 1 \mathrm{~m})$ per hectare, during two years. The accumulated litter in the forest was evaluated through monthly collections in three points. The litter decomposition rate was defined by the quocient between the total annual litter production and the total litter accumulated. The annual production of litter was estimated at $10.305,88 \mathrm{~kg} / \mathrm{ha} / \mathrm{year}$, and the accumulated litter in the forest average $14.296,00 \mathrm{~kg} / \mathrm{ha}$. It was necessary 316 days to decompose $50 \%$ of litter, and decomposition rate corresponded to $\mathrm{K}=0,86$.
\end{abstract}

Key words: araucaria forest, Araucaria angustifolia, national forest, litterfall, decomposition

\section{Introdução}

Vários autores estudaram a dinâmica da Floresta Ombrófila Mista. Britez et al. (1992) avaliaram a produção de serapilheira e macronutrientes em uma floresta com araucária em S. Mateus do Sul, Paraná. Cestaro (1988) estudou o microclima do interior da mata com araucária na Estação Ecológica de Aracuri, Esmeralda, RS e concluiu que a floresta reduz as variações diárias e sazonais das diferentes variáveis climáticas, determinando ambiente mais estável no interior da floresta. L.W. Scheeren (dados não publicados) estudou o efeito dos elementos químicos no crescimento em altura da araucária e constatou existir correlação significativa entre o conteúdo das acículas e o teor de elementos químicos do solo. Schumacher et al. (s/d) estudaram a produção de serapilheira em uma floresta de araucária em Pinhal Grande, RS. Jarenkow \& Baptista (1978) analisaram a composição florística e estrutura da mata com araucária na Estação Ecológica de Aracuri, em Esmeralda e constataram o predomínio estrutural de

\footnotetext{
Universidade do Vale do Rio dos Sinos, Laboratório de Ecologia Vegetal

Alunos de graduação em Biologia, Universidade do Vale do Rio dos Sinos, S. Leopoldo, RS, Brasil

3 Autor para correspondência: albano@bios.unisinos.br
} 
Sebastiania commersoniana e Araucaria angustifolia e que elas são as espécies de maior importância e que o índice de diversidade estimado é dos mais baixos para matas brasileiras multiestratificadas. Fernandes \& Backes (1998) estudaram a produtividade primária em floresta com Araucaria angustifolia no Rio Grande do Sul pela avaliação da produção de serapilheira, da decomposição de matéria orgânica e da produção de $\mathrm{CO}_{2}$ pela degradação de matéria orgânica pela atividade biológica do solo. Backes et al. (2000a) compararam a produção, acúmulo e decomposição de serapilheira de remanescentes de Floresta Ombrófila Mista e de um bosque plantado de Araucaria angustifolia, em São Francisco de Paula, RS e concluíram não haver diferença maior entre a produção de serapilheira em remanescentes de Floresta Ombrófila Mista e bosques plantados de araucária com sub-bosque de angiospermas. No entanto, apresentam grandes diferenças nos índices de decomposição e no conteúdo de nutrientes mensais nas respectivas serapilheiras. Backes (2001) determinou a idade de um povoamento de Floresta Ombrófila Mista e o potencial de regeneração da araucária em Caxias do Sul e concluiu que o povoamento era secundário, as araucárias tinham 50 anos, em média, e apresentavam $40 \mathrm{~cm}$ diâm., em média. Nas condições do povoamento avaliado, a sobrevivência de mudas possibilitava aumento de três novos indivíduos por ano. A. Backes (dados não publicados) avaliou a produção de serapilheira e o balanço de nutrientes em floresta com Araucaria angustifolia no sul do Brasil. G.J. Gerhardt (dados não publicados) estudou a influência dos fatores físicos do solo e dos nutrientes da serapilheira sobre o crescimento em altura da Araucaria angustifolia em Canela, RS e constatou que os nutrientes da serapilheira que têm influência no crescimento da araucária são B, Ca, Cu e Fe. C.A. Cassol (dados não publicados) estudou a relação entre características do solo, crescimento e produtividade em povoamento implantado de Araucaria angustifolia, em Passo Fundo, RS e constatou que os latossolos roxos são os mais apropriados para o crescimento e a produtividade da araucária. A profundidade, a drenagem e a aeração são fatores que atuam decisivamente no desenvolvimento e constituem, freqüentemente, fatores limitantes do desenvolvimento da espécie. Duarte et al. (2002) avaliaram o papel da luz na regeneração de araucária no interior da floresta e concluíram que a araucária é uma espécie tolerante à sombra e a luz não constitui fator limitante para seu desenvolvimento no ambiente florestal. Nascimento et al. (2001) analisaram a estrutura e o padrão de distribuição espacial de espécies arbóreas em uma amostra de Floresta Ombrófila Mista, em Nova Prata e constataram o predomínio da distribuição espacial agregada ou com tendência à agregação. E.A.I. Kindel (dados não publicados) estudou os padrões de dispersão e disposição espacial de Araucaria angustifolia, em Esmeralda e concluiu que a araucária segue um padrão de disposição espacial agregado e atribui o fato aos dispersores. S.J. Longhi (dados não publicados) avaliou comunidades florestais na sub-bacia do Rio Passo Fundo e constatou a dominância da araucária nos povoamentos estudados. Mauhs \& Backes (2002) avaliaram a estrutura fitossociológica e a regeneração natural de um fragmento de Floresta Ombrófila Mista exposto à perturbações decorrentes, principalmente, do pastoreio e concluíram que o fragmento estudado caracterizava-se, sobretudo, pela ausência de espécies normalmente consorciadas à araucária e que, juntamente com esta, constituem, mais comumente, a Floresta Ombrófila Mista no município de Vacaria.

A presente pesquisa teve por objetivo avaliar a produção mensal de serapilheira, a serapilheira acumulada sobre o solo florestal e o tempo necessário para decompor $50 \%$ da mesma de um remanescente de Floresta Ombrófila Mista, na Floresta Nacional de São Francisco de Paula.

\section{Material e métodos}

Em São Francisco de Paula a precipitação média anual é estimada em $2.252,00 \mathrm{~mm}$. Chove regularmente todos os meses do ano e as chuvas mais intensas ocorrem durante a primavera e o verão. O clima é do tipo $\mathrm{Cfb}$, isto é, mesotérmico, superúmido, com verão brando e inverno frio. É freqüente a formação de geada e, mais eventualmente, queda de neve. Toda a região está sujeita a freqüentes e intensos nevoeiros e os ventos predominantes são E/SE/NE (Nimer 1990; Fernandes \& Backes 1998; Backes 1999) (Fig.1).

A Floresta Nacional de São Francisco de Paula está localizada no município de São Francisco de Paula, no Estado do Rio Grande do Sul, Brasil, entre as coordenadas $2^{\circ} 24^{\prime}$ e $29^{\circ} 27^{\prime} \mathrm{S}$ e $50^{\circ} 22^{\prime}$ e $50^{\circ} 25^{\prime} \mathrm{W}$ e sua altitude máxima é de $923 \mathrm{~m}$. Ocupa, atualmente, uma área de 1.606 hectares e está constituída por um mosaico de formações que compreende remanescentes de Floresta Ombrófila Mista, florestas de transição, savanas, bosques plantados de Araucaria 


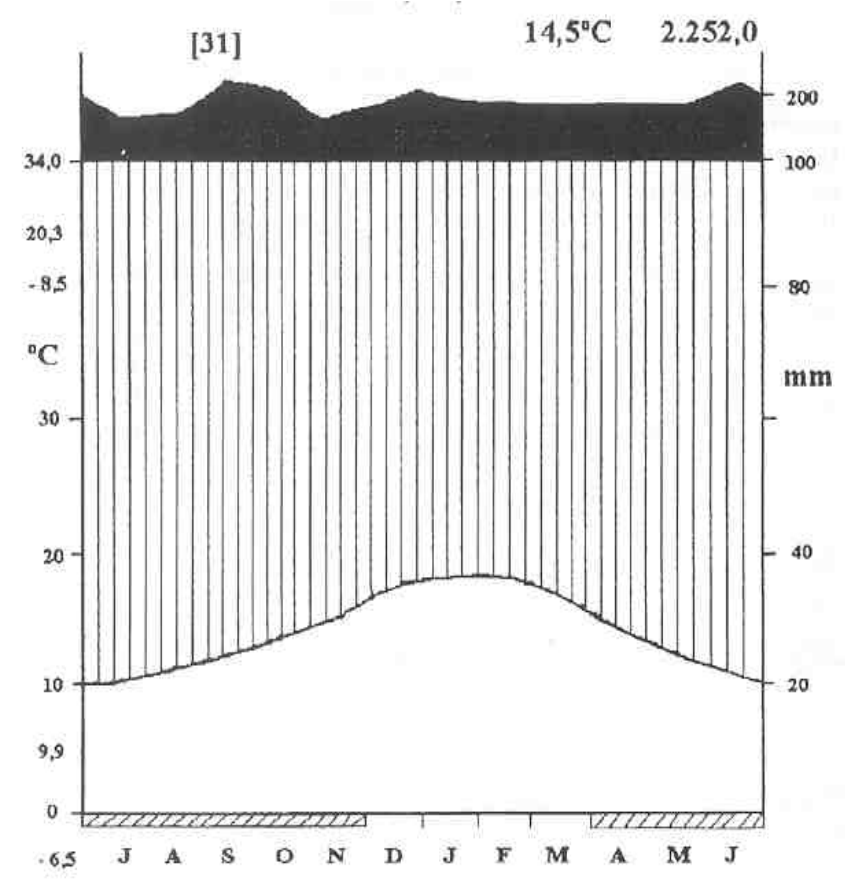

Figura 1. Diagrama climático do município de São Francisco de Paula, RS. Dados fornecidos pelo $8^{\circ}$ Distrito de Meteorologia, com sede em Porto Alegre, do Ministério da Agricultura, RS.

angustifolia, de Pinus elliottii Engelm., Pinus taeda Linn., Cryptomeria japonica (Linn. f.) D. Don. e de Eucalyptus spp. A Floresta Nacional de São Francisco de Paula constitui uma unidade de conservação sob a responsabilidade do Instituto Brasileiro do Meio Ambiente e dos Recursos Naturais Renováveis, (IBAMA), do Ministério do Meio Ambiente. O fragmento de Floresta Ombrófila Mista objeto do presente estudo, é formado por numerosos espécimes de Araucaria angustifolia (Bertol.) Kuntze, sendo que a maioria tem mais de $0,80 \mathrm{~m}$ diâm. e 25 a $30 \mathrm{~m}$ alt., e por diversas espécies consorciadas, entre as quais destacam-se Blepharocalyx salicifolius (H.B. \& K.) Berg, Ilex paraguariensis St. Hil., Tabebuia umbellata (Sond.) Sandwith e várias espécies dos gêneros Ocotea e Nectandra. A avaliação da produção, do acúmulo e da decomposição de serapilheira foi feita à base dos dados coletados durante o período entre janeiro/2001 e janeiro/2003. Para avaliar a produção mensal de serapilheira foram utilizados 15 coletores, medindo cada qual $80 \times 100 \mathrm{~cm}$, distribuídos ao longo de três transectos, espaçados trinta metros, cada um contendo cinco coletores eqüidistantes, com separação de $20 \mathrm{~m}$. Os coletores com fundo de tela de polietileno com malha de $1 \mathrm{~mm}$, permaneceram suspensos a $30 \mathrm{~cm}$ do solo durante o período de coleta. Os resíduos vegetais recolhidos em intervalos de 30 dias foram colocados para secar em estufa a $60^{\circ} \mathrm{C}$ até peso constante e separados nas seguintes categorias: material produzido pela araucária, material produzido pelas espécies latifoliadas e outros materiais. As duas primeiras categorias foram separadas em folhas, ramos e estruturas reprodutivas (flores, frutos e sementes) e a terceira categoria foi separada em cascas, musgos/ liquens e miscelânea.

Foi feita a análise de variância para blocos casualisados considerando os dois anos de avaliação e as quatro estações do ano. A medida de semelhança foi a distância euclidiana entre as unidades amostrais e o critério considerado foi a soma de quadrados das distâncias entre os grupos. O limite de confiança considerado foi de $95 \%$.

\section{Resultados e discussão}

A produção de serapilheira, durante dois anos, foi de $10.305,88 \mathrm{~kg} / \mathrm{ha} / \mathrm{ano}$, em média. Desse total, 59\%, isto é, $6.080,79 \mathrm{~kg}$, provém da araucária, $33,9 \%$, correspondente a $3.494,88 \mathrm{~kg}$, provém das espécies latifoliadas e 7,08\% é constituído por cascas, liquens/ musgos e miscelânea, isto é, material não identificado, que corresponde a 730,20kg (Fig. 2). Da serapilheira proveniente da araucária, 56,3\% corresponde às acículas, $28,21 \%$ a ramos e $15,49 \%$ são estruturas reprodutivas, isto é, sementes e cones de pólen ou de semente. Dos resíduos originados pelas espécies latifoliadas, $68,06 \%$, corresponde às folhas, $29,57 \%$ são ramos e $2,37 \%$ são flores, frutos e sementes. Considerando toda a serapilheira proveniente da

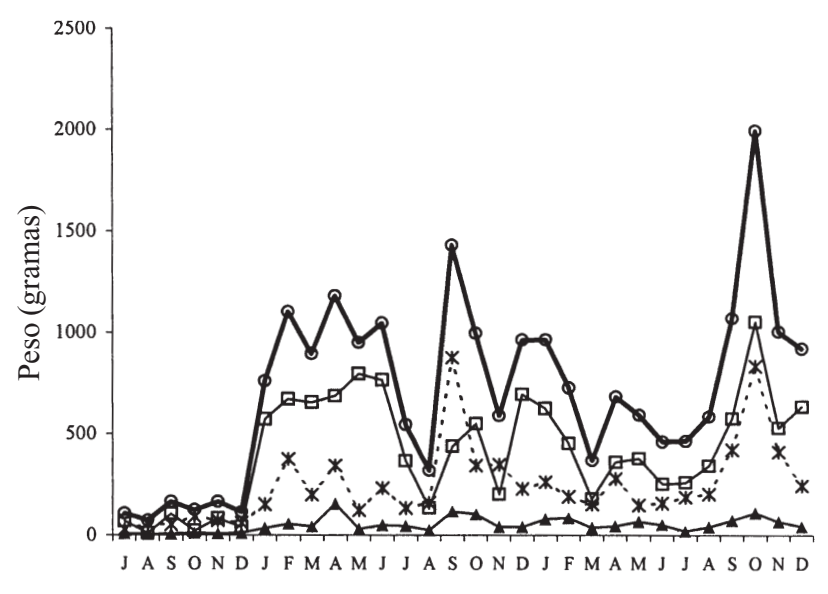

Figura 2. Total de serapilheira recolhida num fragmento de Floresta Ombrófila Mista na Floresta Nacional de São Francisco de Paula, RS, no período de julho/2000 a dezembro/2002. $\square=$ Araucária; -- $*$-- = Latifoliados; $-\boldsymbol{\star}=$ Diversos; $\ominus=$ Total. 
araucária e das latifoliadas em geral, 60,59\% são folhas, $28,71 \%$ são ramos e $10,70 \%$ são estruturas reprodutivas. (Fig. 3-5).

Fernandes \& Backes (1998) estudaram remanescentes de Floresta Ombrófila Mista, na mesma Floresta Nacional, e registraram uma produtividade de $5,9 \mathrm{t} / \mathrm{ha} / \mathrm{ano}$, sendo que $54,7 \%$ correspondeu a folhas, $31,3 \%$ a ramos e $7,9 \%$ a estruturas reprodutivas e $6,1 \%$ de outros materiais. O total registrado por estes autores, comparado com os resultados médios dos dois anos da presente pesquisa, representa um ano de baixa produção. Estudos realizados por Britez et al.(1992) em Floresta Ombrófila Mista, em São Mateus do Sul, Paraná, registraram a produção anual da ordem de $6.526,7 \mathrm{~kg} / \mathrm{ha}$ e consideraram que esse valor encontra-se entre os limites esperados para a latitude de $25^{\circ} 52^{\prime} \mathrm{S}$, admitindo uma relação linear entre a

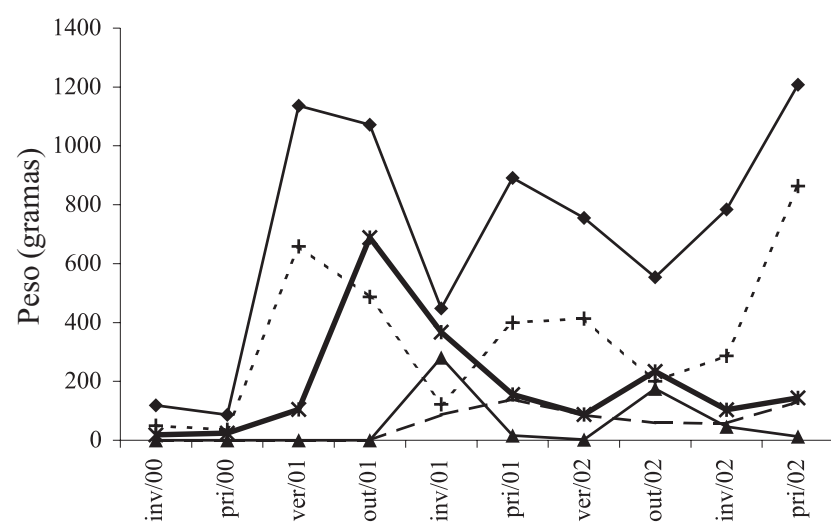

Figura 3. Total de serapilheira recolhida em frações de araucária, num fragmento de Floresta Ombrófila Mista na Floresta Nacional de São Francisco de Paula, RS, por estação. - = Acículas; $--+--=$ Ramos; $-\mathbf{-}=$ Reprodutivos femininos; $-=$ Reprodutivos masculinos; $*-=$ Total de reprodutivos.

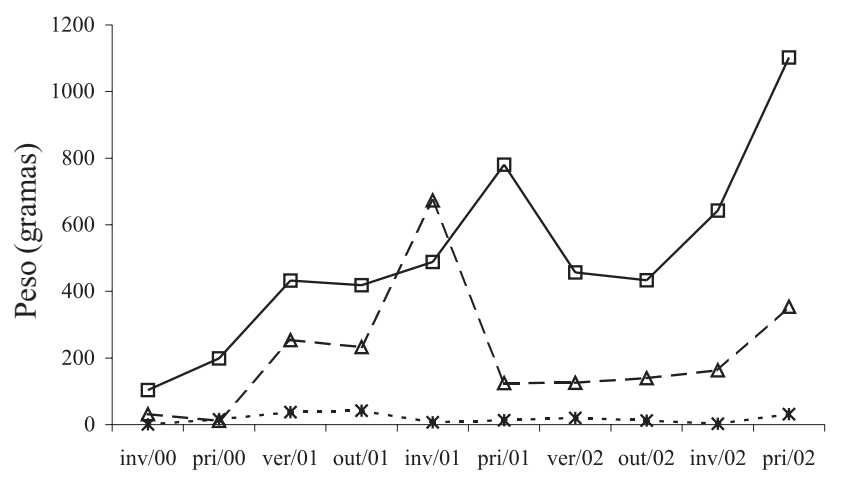

Figura 4. Produção de serapilheira de latifoliadas, num fragmento de Floresta Ombrófila Mista, na Floresta Nacional de São Francisco de Paula, RS, por estação. $\square=$ Folhas; $-\Delta^{-}=$Ramos; --*-- = Reprodutivos.

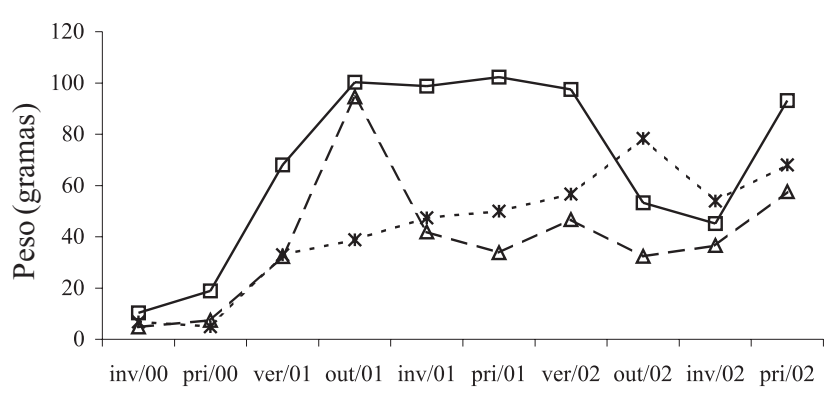

Figura 5. Total da serapilheira recolhida em frações de diversos, num fragmento de Floresta Ombrófila Mista, na Floresta Nacional de São Francisco de Paula, RS, por estação. --*-- = Cascas; $-\triangle-=$ Musgos/líquens; $\square=$ Miscelânia.

produção e a latitude em função da temperatura e da insolação. A média anual de produção de acículas, assim como de folhas de latifoliadas, está de acordo com a estimativa de Bray \& Gorham (1964), mas são inferiores aos de Koehler et al. (1987) em estudos de produção de três sítios no Paraná e o valor maior encontrado foi de $6,4 \mathrm{t} / \mathrm{ha} / \mathrm{ano}$.

A análise de variância permitiu demonstrar que não houve diferença significativa de produção de serapilheira entre os dois anos avaliados $(F>1,0)$. Ocorreram diferenças significativas de produção entre as diferentes frações da serapilheria e as estações do ano. Dessa maneira a produção de acículas de araucária variou significativamente do inverno para a primavera $(P=0,02)$. A produção de ramos de araucária foi também significativamente diferente do inverno para a primavera $(\mathrm{P}=0,01)$. A produção de estruturas de cones de semente e sementes variou significativamente do verão para o outono $(\mathrm{P}=0,002)$, do verão para a primavera $(\mathrm{P}=0,05)$ e do outono para a primavera $(\mathrm{P}=0,001)$. A produção maior ocorreu durante o outono. A queda de estruturas de cones de pólen da araucária variou significativamente do verão para a primavera $(\mathrm{P}=0,03)$ e do outono para a primavera $(P=0,005)$. Durante a primavera ocorreu a maior produção. A queda de folhas de angiospermas variou significativamente entre o verão e a primavera $(P=0,002)$, entre o outono e a primavera $(P=0,001)$ e entre o inverno e a primavera $(\mathrm{P}=0,04)$, sendo que a maior produção ocorreu durante a primavera. A queda de ramos de angiospermas não apresentou variação significativa entre as quatro estações do ano $(\mathrm{P}=0,9)$. A queda de acículas, ramos e estrturuas reprodutivas da araucária, juntamente com as folhas de angiospermas, apresentau acentuada sazonalidade, e, com excessão dos cones de sementes da araucária e dos ramos de angiospermas, a maior produção ocorreu sempre durante a primavera. 
A produção de serapilheira total foi constante durante a maior parte do ano e também não variou significativamente durante os dois anos avaliados $(\mathrm{F}=2)$. Porém, a queda de folhas e acículas aumentou significativamente durante a primavera. A produção de acículas e de ramos da araucária obedeceu a um ciclo com o máximo durante a primavera decrescendo progressivamente até o inverno, durante o qual, foi registrada a menor produção. Britez et al. (1992) procuraram correlacionar a maior queda durante a primavera com o aumento da pluviosidade e da temperatura, à presença de espécies decíduas e à formação de geadas. Registraram para a latitude de $25^{\circ} 52^{\prime} \mathrm{S}$ e altitude de $760 \mathrm{~m}$ e temperatura média anual de $17^{\circ} \mathrm{C}$, uma queda de folhas superior a $62 \%$ durante a primavera, percentual já estimado por Bray \& Gorham (1964). No presente trabalho, o aumento significativo da queda durante a primavera e verão pode estar relacionado com o aumento da precipitação pluviométrica durante esse mesmo período. Na Floresta Nacional, situada a $29^{\circ} \mathrm{S}$, em altitudes acima de $900 \mathrm{~m}$, com temperatura média de $14,5^{\circ} \mathrm{C}$ e precipitação pluviométrica acima de $2.000 \mathrm{~mm}$, o fato das folhas representarem mais de $70 \%$ do total de serapilheira, é conseqüência da senescência das mesmas devido às baixas temperaturas que ocorrem na região durante o inverno imediatamente anterior e à seca fisiológica determinada por temperaturas negativas ou muito próximas a $0^{\circ} \mathrm{C}$ que são freqüentes na região. Representa também um processo de substituição estacional e gradual de estruturas adultas total ou parcialmente envelhecidas, menos eficientes, por folhas novas como conseqüência do intenso crescimento primaveril. Constitui um processo de caducifolia não aparente, pois a queda ocorre de forma sincronizada com a formação de novas folhas.

A queda de sementes e de cones de sementes atingiu sua maior produção durante o outono e o inverno e foi nula durante a primavera e o verão (Fig. 3). A produção de sementes de araucária apresenta flutuações acentuadas de um ano para outro. Anos com produção elevada são seguidos por outros períodos de baixa produção sem que para isso se tenha uma explicação das causas determinantes dessas flutuações. A produção de cones de pólen é marcadamente cíclica. A queda se inicia durante o inverno, alcança o máximo durante a primavera, decresce durante o verão e registra os valores mais baixos durante o outono (Fig. 3). O material colhido durante as duas últimas estações é constituído por cones abertos, destituídos de pólen, pois a liberação do mesmo ocorre durante a primavera, quando as chuvas polínicas podem alcançar grande intensidade.

A floresta acumula $14.296 \mathrm{~kg} / \mathrm{ha}$ de resíduos vegetais e a taxa de decomposição corresponde a $\mathrm{K}=0,86$ e o tempo necessário para decompor $50 \%$ do material vegetal e o tempo médio de renovação foi de 316 dias. Backes et al. (2000a) encontraram $16.766,5 \mathrm{~kg} /$ ha de serapilheira acumulada com uma variação de $9,4 \mathrm{t} / \mathrm{ha}$ a $3,8 \mathrm{t} / \mathrm{ha}$ em duas áreas avaliadas. A avaliação de serapilheira acumulada foi feita exclusivamente na Floresta Nacional de S. Francisco de Paula e nenhum outro trabalho foi realizado em outra região. Existem informações relativas a outras fitocenoses brasileiras. Meguro et al.(1979) estimaram em $6.655,0 \mathrm{~kg} / \mathrm{ha}$ a serapilheira acumulada em uma mata secundária, em S. Paulo. Avaliações em floresta Ombrófila Densa, Varjabedian \& Pagano (1988) obtiveram valores que variaram entre 7,5 a $15,5 \mathrm{t} / \mathrm{ha}$. Em Floresta Estacional Semidecidual, Pagano (1989) registrou 5,7t/ha. Leitão Filho et al. (1993) registraram em Floresta Ombrófila Densa, valores que variaram entre 3,9 a 5,8t/ha. Os valores estimados pela presente pesquisa estão muito acima dos valores registrados para fitocenoses tropicais, indicando a tendência de acumular material, devido à maior lentidão dos processos de decomposição, pois o tempo necessário para a renovação ultrapassa um ano, determinando, dessa maneira, acúmulo de material. Segundo Fernandes \& Backes (1998), os processos de decomposição são influenciados pelas variações sazonais, principalmente da temperatura, sendo acelerados durante os meses mais quentes e desacelerados durante os meses mais frios. No entanto, a queda da serapilheira é praticamente contínua durante todo o ano e, em conseqüência, aumenta a quantidade de resíduos vegetais acumulados sobre o solo da floresta.

A queda de folhas de angiospermas aumentou a partir do inverno, atingiu o máximo durante a primavera e diminuiu, mas manteve-se constante durante o verão e o outono. Backes et al. (2000b) avaliaram dois remanescentes de Floresta Ombrófila Mista, localizados na Floresta Nacional e registraram a produção média das duas áreas de $7.250 \mathrm{~kg} / \mathrm{ha} / \mathrm{ano}$. Desse total a araucária contribuiu com $62,8 \%$ e as latifoliadas com $29,29 \%$. As acículas representaram $62,38 \%$ e as folhas das latifoliadas $73,6 \%$.

Bray \& Gorham (1964) estimaram para a latitude de $29^{\circ} \mathrm{N}$ uma produção de $7,0 \mathrm{t} / \mathrm{ha} / \mathrm{ano}$. No presente trabalho para a latitude de $29^{\circ} \mathrm{S}$, a produção foi de 10,3t/ha/ano, o que pode indicar maior eficiência dos processos de produção da floresta estudada. 
Para altitudes entre 850 e $1.050 \mathrm{~m}$, Bray \& Gorham (1964) estimaram a produção de serapilheira em 3,6 tha/ano, portanto muito inferior à produção registrada pelo presente trabalho.

Os sistemas florestais mistos, que no presente estudo compreendem florestas formadas por coníferas de clima temperado, que formam o estrato superior $\mathrm{e}$ consorciadas com espécies latifoliadas tropicais que formam os estratos inferiores, constituem sistemas florísticos e estruturais heterogêneos e mais complexos, capazes de desenvolver estratégias que ampliam suas variáveis funcionais, possibilitando alcançar, desta maneira, maior eficiência em todos os processos.

\section{Agadecimentos}

Os autores agradecem à Diretoria do IBAMA do Rio Grande do Sul, pela autorização para desenvolver a pesquisa na Floresta Nacional de São Francisco de Paula; ao Diretor e Funcionários da FLONA, pelo apoio durante a realização dos trabalhos na floresta; à FAPERGS, pelo auxílio financeiro; à Universidade do Vale do Rio dos Sinos, pelo estímulo à pesquisa.

\section{Referências bibliográficas}

Backes, A. 1999. Condicionamento climático e distribuição geográfica de Araucaria angustifolia (Bertol.) Kuntze no Brasil - II. Pesquisas, Botânica 19: 31-51.

Backes, A. 2001. Determinação da idade e regeneração natural de uma população de Araucaria angustifolia (Bertol.) Kuntze em um povoamento florestal localizado no município de Caxias do Sul, RS, Brasil. Iheringia, Série Botânica 56: 115-130.

Backes, A.; Fernandes, A.V. \& Zeni, D.J. 2000a. Produção de folhedo em uma floresta com Araucaria angustifolia no Sul do Brasil. Pesquisas, Botânica 50: 92-117.

Backes, A.; Fernandes, A.V. \& Zeni, D.J. 2000b. Produção de serapilheira em uma floresta com Araucaria angustifolia no Sul do Brasil. V Simpósio de Ecossistemas Brasileiros. Conservação. Vitória 2000. Anais 3: 247-266.

Bray, J.R. \& Gorham, E. 1964. Litter production in forest of the world. Advances in Ecological Research 2: 101-157.
Britez, R.M.; Reissmann, C.B.; Silva, S.M. \& Santos Filho, A. 1992. Deposição estacional de serapilheira e macronutrientes em uma floresta de araucária, São Mateus do Sul,Paraná. $2^{\circ}$ Congresso Nacional sobre essências nativas. Anais: 766-772.

Cestaro, L.A. 1988. Estudo microclimático do interior de uma mata de araucária na Estação Ecológica de Aracuri, Esmeralda, RS. Revista Árvore 12(1): 41-57.

Duarte, L.S.; Dillenburg, L.R. \& Rosa, L.M. 2002. Assessing the role of light avaliability in the regeneration of Araucaria angustifolia (Araucaricaceae). Australian Journal of Botany 50: 741-751.

Fernandes, A.V. \& Backes, A. 1998. Produtividade primária em floresta com Araucaria angustifolia no Rio Grande do Sul. Iheringia, Série Botânica 51(1): 63-78.

Jarenkow, J.A. \& Baptista, L.R.M. 1978. Composição florística e estrutura da mata com araucária na Estação Ecológica de Aracuri, Esmeralda, Rio Grande do Sul. Napaea 3: 9-18.

Koehler, C.W.; Reissmann, C.B. \& Koehler, H.S. 1987. Deposição de resíduos orgânicos (serapilheira) e nutrientes em plantio de Araucaria angustifolia em função do sítio. Revista do Setor de Ciências Agrárias 9: $89-94$

Leitão-Filho, H.F. et al. 1993. Ecologia da mata Atlântica em Cubatão. São Paulo. Editora da Universidade Estadual Paulista, Editora da Universidade de Campinas.

Mauhs, J. \& Backes, A. 2002. Estrutura fitossociológica regeneração natural de um fragmento de Floresta Ombrófila Mista exposta à perturbações antrópicas. Pesquisas, Botânica 52: 89-109.

Meguro, M.; Vinueza, G.N. \& Delitti, W.B.C. 1979. Ciclagem de nutrientes minerais na mata mesófila secundária. Parte 1: Produção e conteúdo de nutrientes minerais no folhedo. Boletim de Botânica 7: 11-31.

Nascimento, A.R.T.; Longhi, S.J. \& Brena, D.A. 2001. Estrutura e padrões de distribuição espacial de espécies arbóreas em uma amostra de Floresta Ombrófila Mista, em Nova Prata, RS. Ciência Florestal 11(1): 105-119.

Nimer, E. 1990. Clima. Geografia do Brasil, v. 2, Região Sul: 151-187.

Pagano, S.N. 1989. Produção de folhedo em mata mesófila semidecídua no município de Rio Claro, SP. Revista Brasileira de Biologia 49(3): 633-639.

Schumacher, M.V.; Hernandes, J.J. \& Sutilli, F.J. s/d. Produção de serapilheira uma floresta de Araucaria angustifolia (Bert.) Kuntze no município de Pinhal Grande, RS. Ciclo de Atualização Florestal do Cone Sul: 177-181.

Varjabedian, R. \& Pagano, S.N. 1988. Produção e decomposição de folhedo em um trecho de mata atlântica de encosta no município de Guarujá, S. P. Acta Botanica Brasílica 1(2): 243-256. 